\title{
man \\ SEM-EDX Analysis of Metal Particles Deposition from Surgical Burs after Implant Guided Surgery Procedures
}

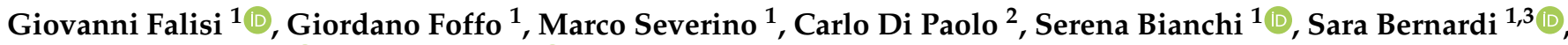 \\ Davide Pietropaoli ${ }^{1}{ }^{\circledR}$, Sofia Rastelli ${ }^{1}{ }^{(0}$, Roberto Gatto ${ }^{1}$ and Gianluca Botticelli ${ }^{1, *}$
}

1 Department of Life, Health and Environmental Sciences, University of L'Aquila, 67100 L'Aquila, Italy; giovanni.falisi@univaq.it (G.F.); giordano.foffo@gmail.com (G.F.); marcoseverino1@gmail.com (M.S.); serena.bianchi@univaq.it (S.B.); sara.bernardi@univaq.it (S.B.); davide.pietropaoli@univaq.it (D.P.); sofiarastelli3@gmail.com (S.R.); roberto.gatto@univaq.it (R.G.)

2 Department of Oral and Maxillo-Facial Sciences, "Sapienza" University of Rome, 00185 Rome, Italy; carlo.dipaolo@uniroma1.it

3 Center of Microscopy, University of L'Aquila, 67100 L'Aquila, Italy

* Correspondence: gianluca.botticelli@graduate.univaq.it

check for updates

Citation: Falisi, G.; Foffo, G.;

Severino, M.; Di Paolo, C.; Bianchi, S.; Bernardi, S.; Pietropaoli, D.; Rastelli, S.; Gatto, R.; Botticelli, G. SEM-EDX Analysis of Metal Particles Deposition from Surgical Burs after Implant Guided Surgery Procedures. Coatings 2022, 12, 240. https:/ / doi.org/10.3390/coatings12020240

Academic Editor: David Schaubroeck

Received: 29 December 2021

Accepted: 9 February 2022

Published: 12 February 2022

Publisher's Note: MDPI stays neutral with regard to jurisdictional claims in published maps and institutional affiliations.

Copyright: (c) 2022 by the authors. Licensee MDPI, Basel, Switzerland. This article is an open access article distributed under the terms and conditions of the Creative Commons Attribution (CC BY) license (https:// creativecommons.org/licenses/by/ $4.0 /)$

\begin{abstract}
The preparation of the implant site in guided surgery procedure takes place without irrigation, which could lead to increased friction of the drills with the formation and release of debris or metal particles. The presence of metal particles in the peri-implant tissue could represent a trigger for macrophage activity, bone resorption processes, and consequent implant loss. According to the guided surgical protocol, the study aimed to evaluate the presence of metal particles deposited during implant site preparation. Twenty-five adult porcine ribs from the same adult individual were chosen due to their trabecular bone structure, similar to facial bones. The samples were all $8 \mathrm{~cm}$ (length) $\times$ $3 \mathrm{~cm}$ (depth) $\times 2 \mathrm{~cm}$ (width) and were further subdivided to obtain 50 elements of $4 \mathrm{~cm} \times 3 \mathrm{~cm} \times$ $2 \mathrm{~cm}$. Plexiglass was used to create structures such as surgical guides so that their function could be mimicked, and the guided implant site preparation sequence could be performed with them. The drill kit used in this study is a guided surgery drill kit characterized by high wear resistance, high yield strength, and good corrosion resistance. This same kit was used 50 times in this way to prepare 50 different implant sites and evaluated at different edges and number of preparation (T0-neutral edge, T1-1 full preparation, T2-10, T3-20, T4-30, T5-40, and T6-50) by SEM-EDX to assess the presence of any metal deposition. The presence of metal residues in the implant site increased according to the cycles of use of the drills. We have observed that in the first three groups, there is no presence of metals. This is evident in groups T3 and T4. Finally, the presence of metal residues becomes significant in the study's last two groups of samples. The study highlighted how the lack of irrigation in the work site leads the deposition of metal particles and in addition to a reduction in the efficiency of the drills, resulting in less precise cutting, altering the shape of the prepared site, and, lastly, reducing the primary stability of the implants.
\end{abstract}

Keywords: implant guided surgery; metal particles deposition; periimplantitis

\section{Introduction}

The success of implant therapy is determined by the functional osseointegration, which in turn depends on a series of factors, such as the chemical, mechanical, and surface characteristics of the used materials, the preparation technique, primary stability, and the host's repair processes during the loading phase [1]. Implants' surgical procedures require drills and implant fixture placement, which is mainly composed of metal alloys, highly biocompatible [2]. The implant fixtures are mostly made of titanium-derived alloys (Ti-6Al-4V) due to biocompatibility, corrosion, and mechanical resistance properties [2]. In particular, when titanium is exposed to air, it forms a film consisting of amorphous 
titanium dioxide $\left(\mathrm{TiO}_{2}\right)$ on the surface of the titanium, which makes the surfaces biocompatible and resistant to corrosions [3-5]; instead, the drill-bits used for the implant site's preparation are made of surgical steel. However, the use of the bits during the time might lead to the loss of cutting edge and the deposition of metal particles on the bone surfaces, lowering the quality of the receiving implant site [6-9]. Metal implants are used mainly in orthopedics for joints replacements and in dentistry to rehabilitate edentulism. Despite the high quality achieved by the metal alloys mentioned above, failures in orthopedic joints replacements, in which friction between two artificial parts can play a crucial role, and the recent histological studies on the bone surrounding implants using animal models, showed the presence of metal debris derived from the phenomenon of oxidation of the material of which the implant is composed [9-11]. Lugowki et al., assessed the presence of low levels of metal debris in different organs (liver, brain, kidney, lung, spleen) after dental implants' placements in the rabbit model [12]. Coen et al. showed how metal debris induces genomic instability in cell cultures [13]. The presence of such debris can determine a phenomenon of aseptic peri-implant osteolysis triggered by an innate immune response, a non-specific foreign body reaction, which includes the presences of foreign body giant cells, macrophages, occasional lymphocytes, fibroblasts, and osteoclasts at the bone-implant interface $[14,15]$. The periprosthetic inflammatory cells around the prosthesis start the inflammatory cascade with the production of pro-inflammatory cytokines, chemokines for inflammatory cells, prostaglandins, and so on [14,15]. What would result from all this would be the failure of the implant due to lack of osseointegration [16,17]. According to the most recent classification of periodontal and peri-implant diseases [18] by the American Academy of Periodontology (AAP) and the European Federation of Periodontology (EFP), the definitions of mucositis and peri-implantitis emerge as a new main character of pathological conditions of tissues surrounding and supporting the dental implants. As the oral cavity is an environment rich in bacteria of hundreds of different species, it has always been quite natural to correlate a large part of the pathological phenomena linked to dental practice with them, considering the abundant sources of evidence [19-21]. However, studies linked to orthopedic prostheses have opened new perspectives in evaluating phenomena linked to peri-implant osteolysis [22]. We know orthopedics uses prostheses that exploit the phenomenon of osseointegration to allow the functionalization of compromised anatomical districts similar to what happens in dental implantology. In the latter case, the key to success lies in the osteointegration of the materials that make up the prosthesis (titanium, cobalt, chromium, zirconia, iron, nickel, molybdenum, aluminum) [23]. Research analyzing the long-term follow-up of hip prosthesis failures has shown that an overwhelming percentage of these failures are related to osteolysis resulting from an immunological reaction to the release of metal particles and ions into the peri-implant space. Survival rates of total joint replacements are $85 \%$ after 25 years of follow-up, with only $7 \%$ of all revisions in orthopedics caused by infection [24]. Thus, a considerable proportion of the long-term failures of orthopedic prostheses can reasonably be attributed to the release of their component metals at the site where they are placed. The same phenomenon would not have been so evident if it had occurred inside the oral cavity, where the formation of a periprosthetic space resulting from aseptic osteolysis would, in any case, be secondarily colonized by the bacterial flora present in the mouth [25]. The exact mechanism could presumably result from surgical tips and burs debris after several usage and sterilization cycles. In addition, debris may not be appropriately removed during guided surgery protocols that include surgical templates due to the lack of washing with physiological solution [26]. The main objective of this in vitro study is to evaluate the presence of metal residues that derive from the surgical protocol using a guided surgery template.

\section{Materials and Methods}

\subsection{Study Design and Samples Preparation}

The study design included a choice of bone samples with structure and properties similar to the jawbones, the fabrication of surgical guides, and the observation and the 
analysis of the treated samples using scanning electron microscopy and energy dispersive X-ray spectrometry (SEM-EDX).

Porcine ribs, derived from a 15-months-old pig from the local slaughterhouse (Figure 1) were chosen, as their trabecular bone structure is similar to that of human facial bones [27].

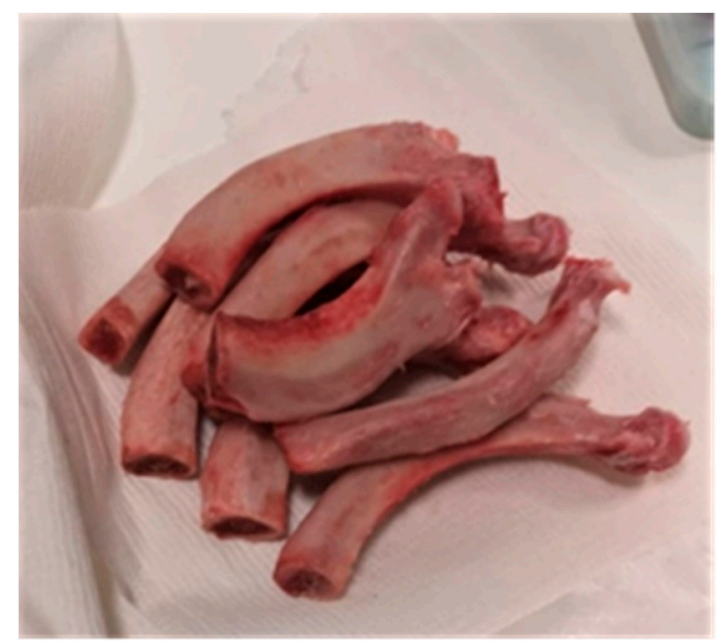

Figure 1. Porcine ribs used for the study.

Twenty-five rib sections taken from the same individual were used. The samples were all $8 \mathrm{~cm}$ (length) $\times 3 \mathrm{~cm}$ (depth) $\times 2 \mathrm{~cm}$ (width) and were further subdivided to obtain 50 elements of $4 \mathrm{~cm} \times 3 \mathrm{~cm} \times 2 \mathrm{~cm}$. The chosen portion of used bone was the central one to adequately represent both medullary and cortical bone. The bone density was similar to D2-D3, according to Misch's classification [28].

Plexiglass was used to create structures similar to surgical guides (Figure 2) so that their function could be mimicked and the guided implant site preparation sequence could be performed with them.

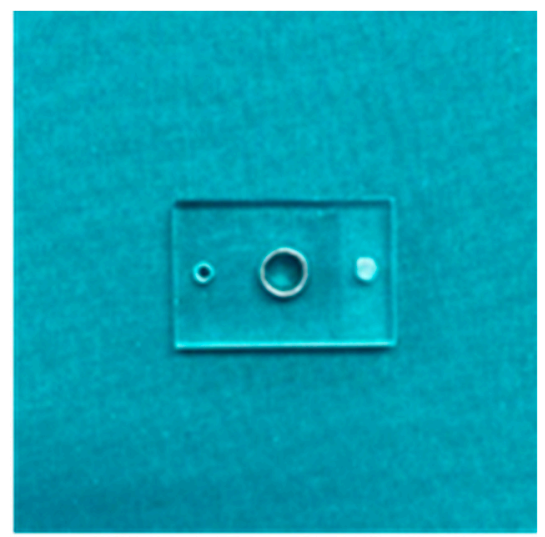

Figure 2. Template to simulate a surgical guide in plexiglass.

The drill kit used in this study is a guided surgery drill kit TKD-GUIDED T8C (AB Dental, Ashdod, Israel). The material of the burs is 17-4PH h 900 martensitic surgical steel, which is characterized by high wear resistance, high yield strength, and good corrosion resistance (Table 1). Therefore, this same kit was used 50 times to obtain 50 different implant sites, and seven follow-ups were chosen to be evaluated at the SEM-EDX (GeminiSEM 500, Zeiss, Jena, Germany). Samples T0, T1, T10, T20, T30, T40, and T50 (where the number indicates the number of complete preparations using surgery protocol) were subjected to EDX investigation. 
Table 1. Elemental composition of 17-4PH h 900 martensitic surgical steel.

\begin{tabular}{|c|c|c|c|c|c|c|c|c|c|}
\hline Type & Crwt\% & $\mathrm{Ni} w \mathrm{t} \%$ & Cu wt\% & Cb-Ta wt $\%$ & C wt $\%$ & Mn wt $\%$ & P wt $\%$ & S wt $\%$ & Si wt $\%$ \\
\hline 17-4PH h 900 & $\begin{array}{c}\text { Min } 15 \\
\operatorname{Max} 17.5\end{array}$ & $\begin{array}{l}\text { Min } 3.0 \\
\text { Max } 5.0\end{array}$ & $\begin{array}{l}\text { Min } 3.0 \\
\text { Max } 5.0\end{array}$ & $\begin{array}{l}\text { Min } 0.15 \\
\text { Max } 0.45\end{array}$ & $0.07 *$ Max & 1.00 Max & $0.04 *$ Max & $\begin{array}{l}0.03^{*} \\
\operatorname{Max}\end{array}$ & 1.00 Max \\
\hline
\end{tabular}

* below detection limit $=0.1 \mathrm{wt} \%$.

\subsection{Guided Surgery Protocol}

First, the surgical guide made from Plexiglas was stabilized on the specimens to be prepared using osteosynthesis screws (Figure 3A). The drill bits were then used to prepare the implant site in the ribs using the sequential technique prescribed and indicated by the manufacturer of the drills (Figure 3B).

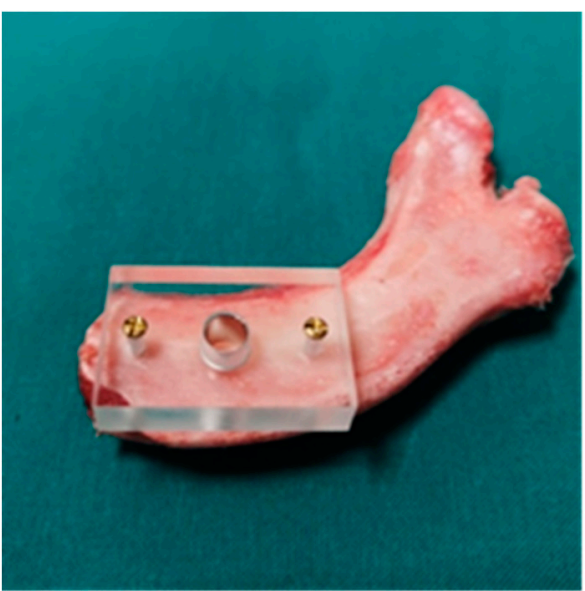

(A)

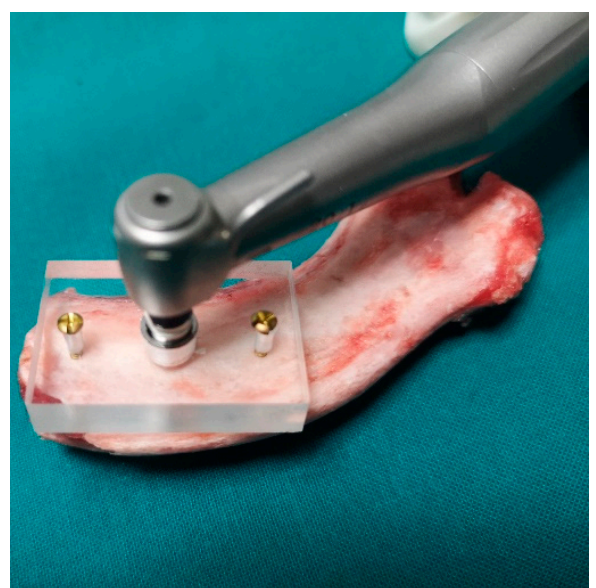

(B)

Figure 3. (A) Fixation of the surgical guide on the surface of the rib. (B) Implant site preparation.

The guided technique includes:

- $\quad$ As a first step, the use of the lanceolate bur;

- The subsequent corticotomy with the $2 \mathrm{~mm}$ diameter (2D) and $6 \mathrm{~mm}$ length bur;

- $\quad$ Deepening of the preparation with the D2 and $11.5 \mathrm{~mm}$ length bur;

- $\quad$ Expansion of the site with burs in sequence:

- $\quad$ A bur of $2.8 \mathrm{~mm}$ diameter and $11.5 \mathrm{~mm}$ length;

- A bur of $3.2 \mathrm{~mm}$ diameter and $11.5 \mathrm{~mm}$ length;

- $\quad$ Final preparation with a bur of 3.65 diameter and $11.5 \mathrm{~mm}$ length.

The preparations were carried out using an NSK Surgic Pro with X-DSG20 handpiece (NSK/Nakanishi inc., Kanuma, Japan), with a speed of $150 \mathrm{rpm}$ and a torque of $60 \mathrm{Nm}$, without irrigating solution as described above.

All preparations were carried out using a surgical guide, which allowed the correct orientation of the drill to be maintained. In addition, a load-cell was placed under the area of the implant site to maintain a constant working pressure (9.81 to $14.71 \mathrm{~Pa}$ ) on the drill bits.

At the end of use, every drill was subjected to a regular cleaning and rapid sterilization process, as follows: initial cleaning was carried out with a brush and detergent. The cutters were then subjected to a cleaning cycle in an ultrasound tank for $5 \mathrm{~min}$ and finally sterilized in a class B autoclave with a flash cycle at $134{ }^{\circ} \mathrm{C}$ for $5 \mathrm{~min}$ [29]. After the surgical preparation, the samples were sliced using a manual saw directed parallelly to the axes of the preparation.

\subsection{SEM-EDX}

The preparation protocol of bone samples for SEM observation was followed as described: after fixing the samples with glutaraldehyde, the bones were rinsed with distilled 
water to remove the fixative and were dehydrated in an ascending series of alcohols (50\%, $75 \%, 95 \%, 100 \%)$, left to dry on absorbent paper for $48 \mathrm{~h}$ and observed with the scanning electron microscope. For all the samples, the chosen area included the cortical and part of the medullar portion (Figure 4). The areas were observed randomly in different positions at different degrees of magnification in secondary electron (SE) mode. The parameters used were accelerating voltage (AV) $7.00 \mathrm{kV}$, spot size $20 \mu \mathrm{m}$, and working distance between 13.6 and $14.1 \mathrm{~mm}$.

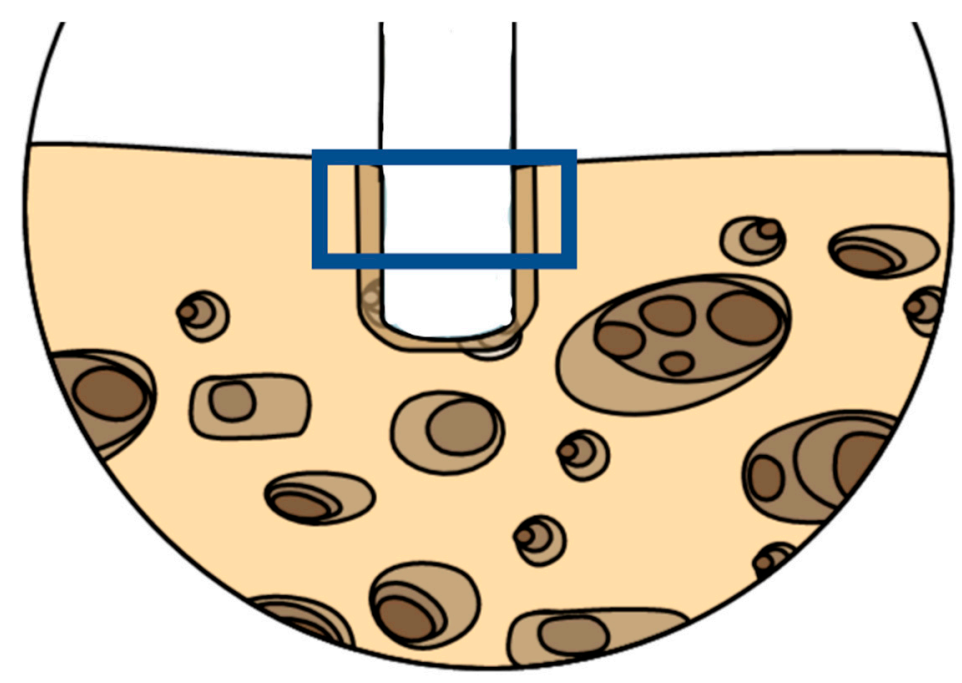

Figure 4. Representative scheme of the chosen area observed at the SEM-EDX to spot the metal particles debris. Picture realized using Mindthegraph ${ }^{\circledR}$ infograph software (https:/ / mindthegraph. $\mathrm{com} /$, accessed on 1 February 2022).

\subsection{Statistical Analysis}

The considered endpoint was the number of fields where it was possible to detect metal debris using SEM-EDX. Due to the small sample size, a non-parametric approach was applied. Wilcoxon test was used to analyse the data using Bonferroni correction for multiple comparisons. T0 was set as the reference for multiple comparisons. Significance was set with a $p$-value $<0.05$. Analysis was performed using R software (v4.02).

\section{Results}

From the SEM-EDX analysis, it was possible to observe and compare the different samples and the presence of eventual metal particles.

In particular, sample $\mathrm{T} 0$, the control rib, shows no metals and a trabecular structure and composition typical of bone tissue (Figure 5).

Samples T1 and T2, comprising the group in which all the preparation sites were carried out with cutters used from the first cycle to a maximum of 10 cycles of use and sterilization, show no metal residues due to preparation (Figure 6). Samples T3 and T4 showed small fields of residues (Figure 7), the presence of which increased in samples T5 and T6, which have undergone 30 to 50 cycles of use.

It was possible to detect more residue fields at the site, up to five (Figures 8 and 9). The geometry of the preparation of the last groups tends to be more irregular due to reducing the cutting efficiency of the cutters. The elements found as residues of the preparation are $\mathrm{Ti}, \mathrm{Fe}, \mathrm{Cr}, \mathrm{Al}$ (titanium, iron, chromium, aluminum). 


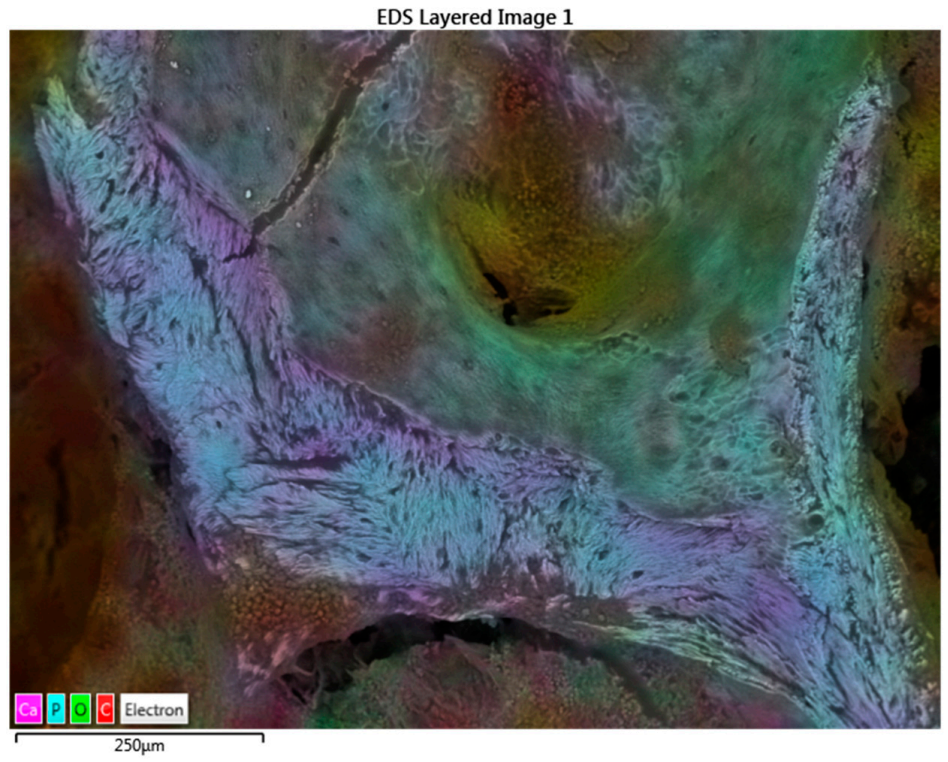

Figure 5. SEM-EDX map factor of the T0 sample. The map factor allowed us to observe the distribution of the $\mathrm{Ca}, \mathrm{P}, \mathrm{O}$, and $\mathrm{C}$ electrons that compose the bone.
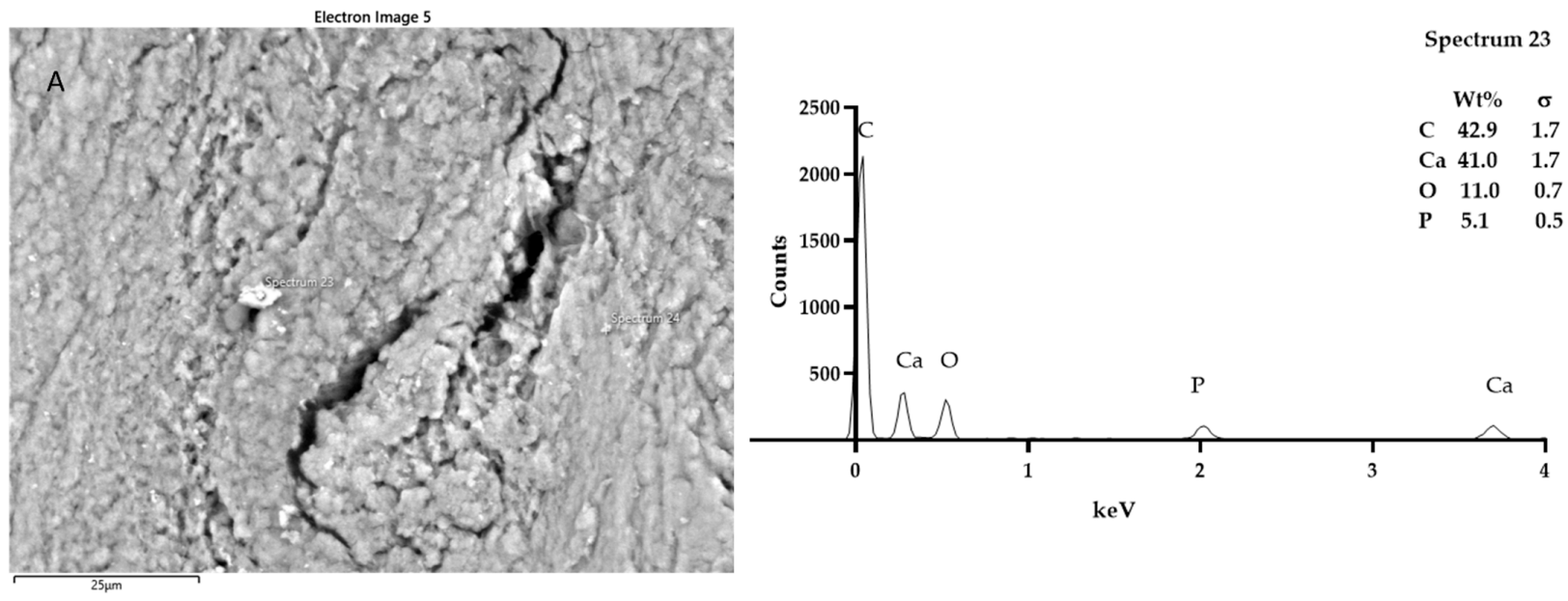

$\mathrm{keV}$
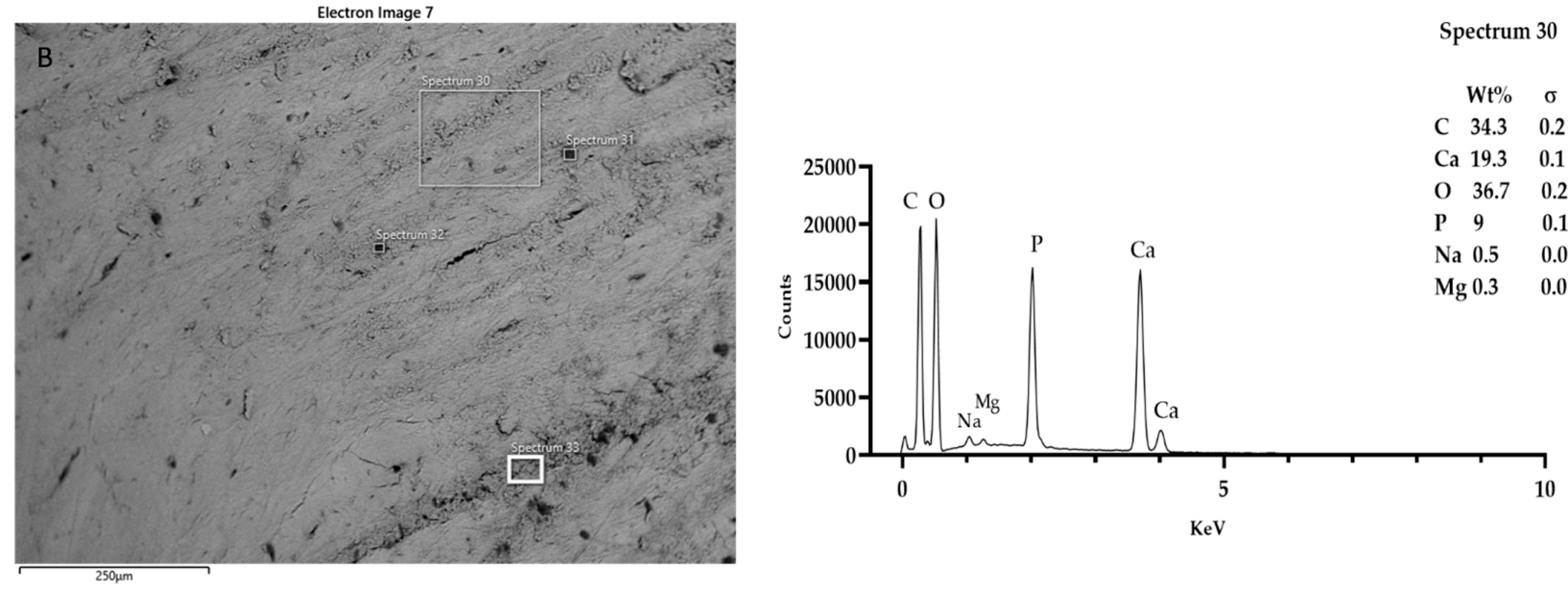

Figure 6. SEM-EDX analysis of samples T1 (A) and T2 (B). Looking at the morphology of the bone tissue of the samples T1 and T2, it was possible to notice some somewhat luminescent particles. However, the particles analyzed in T1 and T2 had the typical composition of bone tissue: calcium phosphate and carbon. Spectra outputs were realized using GrapPad Prism 9.3.1. 

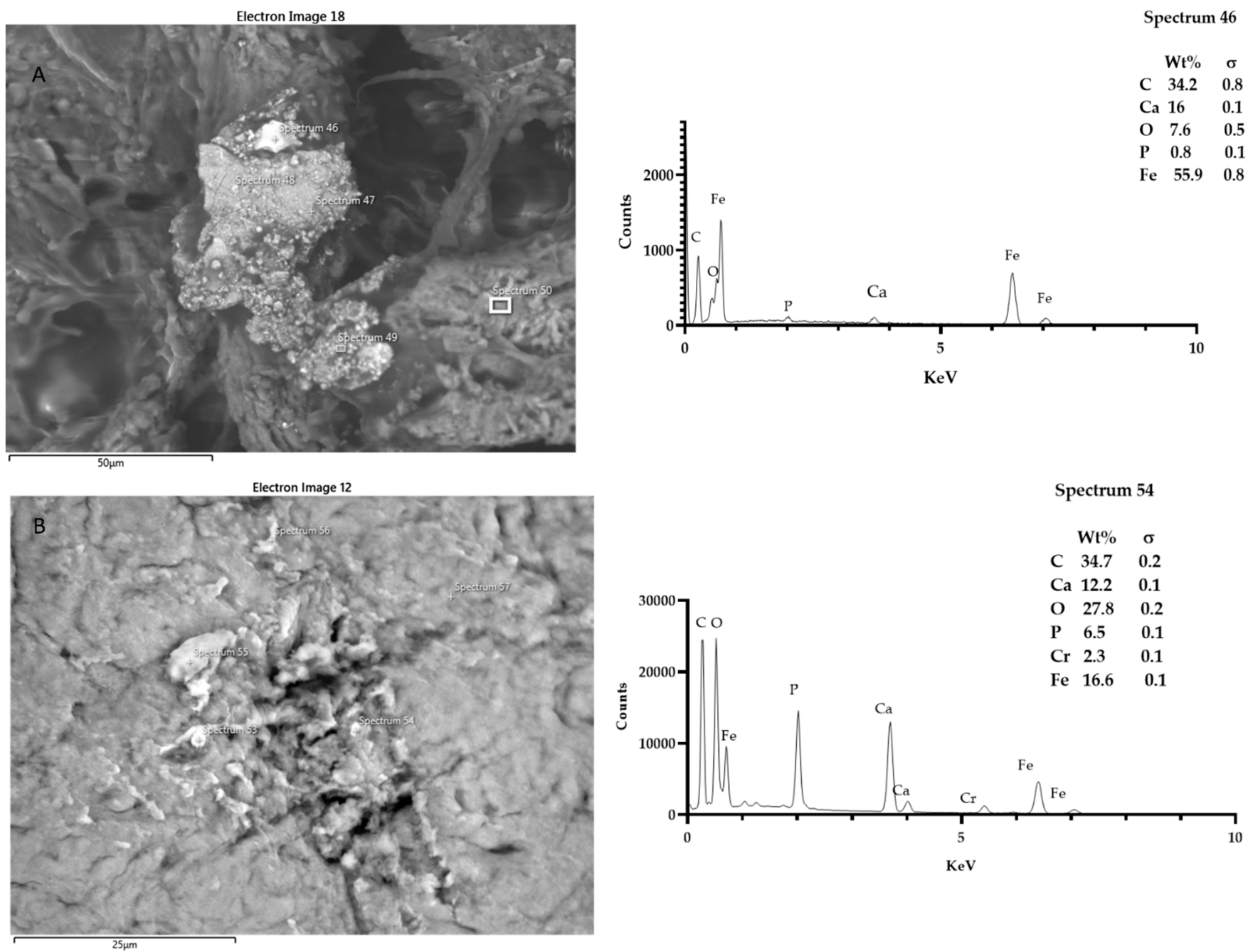

Figure 7. SEM-EDX analysis of samples T3 (A), and T4 (B). Regarding T3 and T4 samples, the presence of a few fields showing electron beam reactive particles could be observed. Microanalysis showed the presence of iron particles and chrome in addition to calcium phosphate. Spectra outputs were realized using GrapPad Prism 9.3.1.

The differences between the samples were statistically significant (Figure 10). In particular, statistical analysis showed a significant difference in metal particle presence in sample $\mathrm{T} 5$ when compared with the T0 sample. In addition, the Bonferroni correction for multiple comparisons showed a significant difference in T4, T5, and T6 samples with respect to $\mathrm{T} 1, \mathrm{~T} 2$, and $\mathrm{T} 3$ samples. 

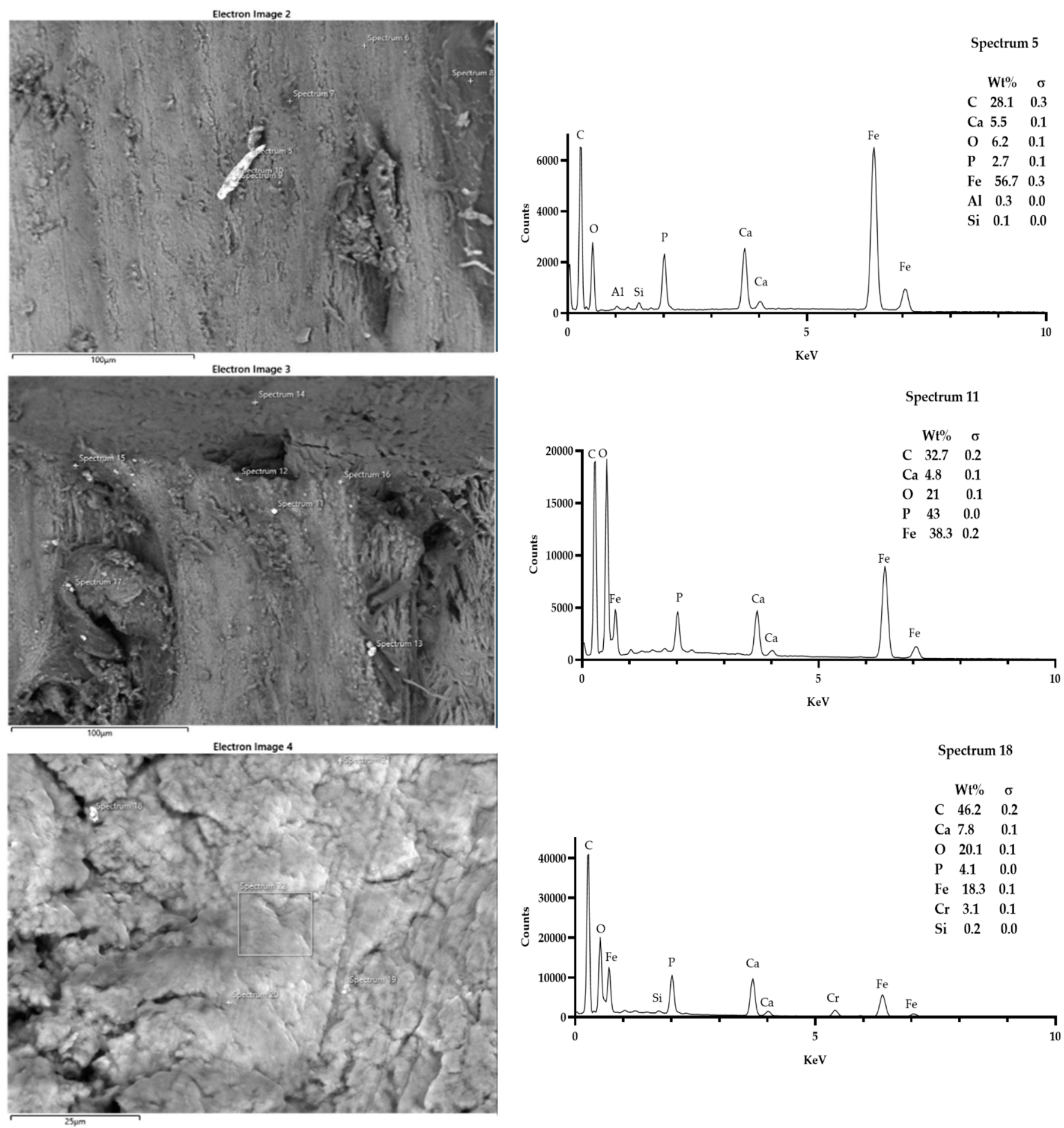

Figure 8. Sample T5. It was possible to spot up to three fields, showing the presence of particles that were morphologically reactive. The microanalysis showed the presence of iron, aluminum, siliceous, and chrome. Spectra outputs were realized using GrapPad Prism 9.3.1. 

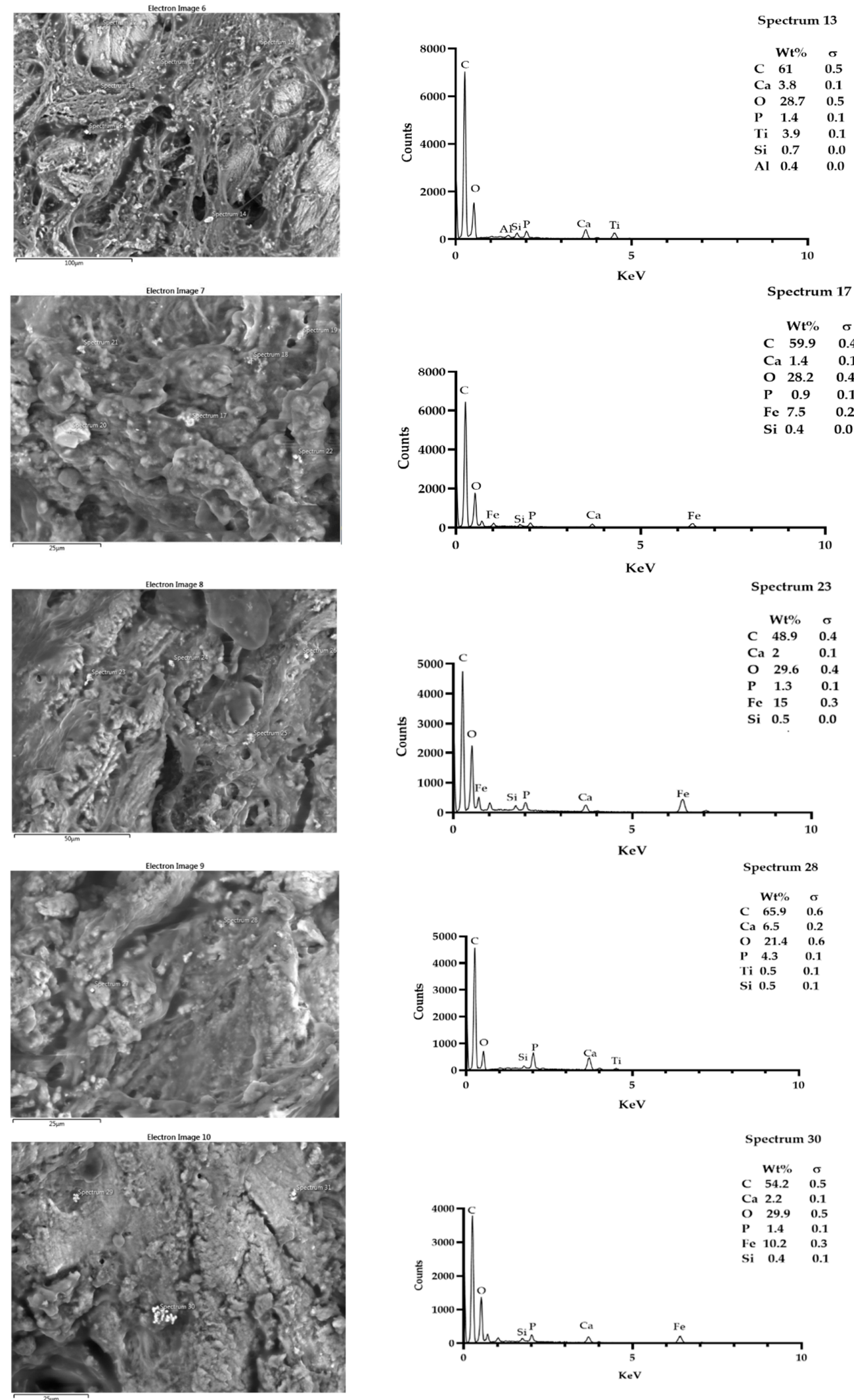

Figure 9. Sample T6. It was possible to spot up to five fields, showing the presence of particles that were morphologically reactive. The microanalysis showed the presence of titanium, iron, and siliceous. Spectra outputs were realized using GrapPad Prism 9.3.1. 


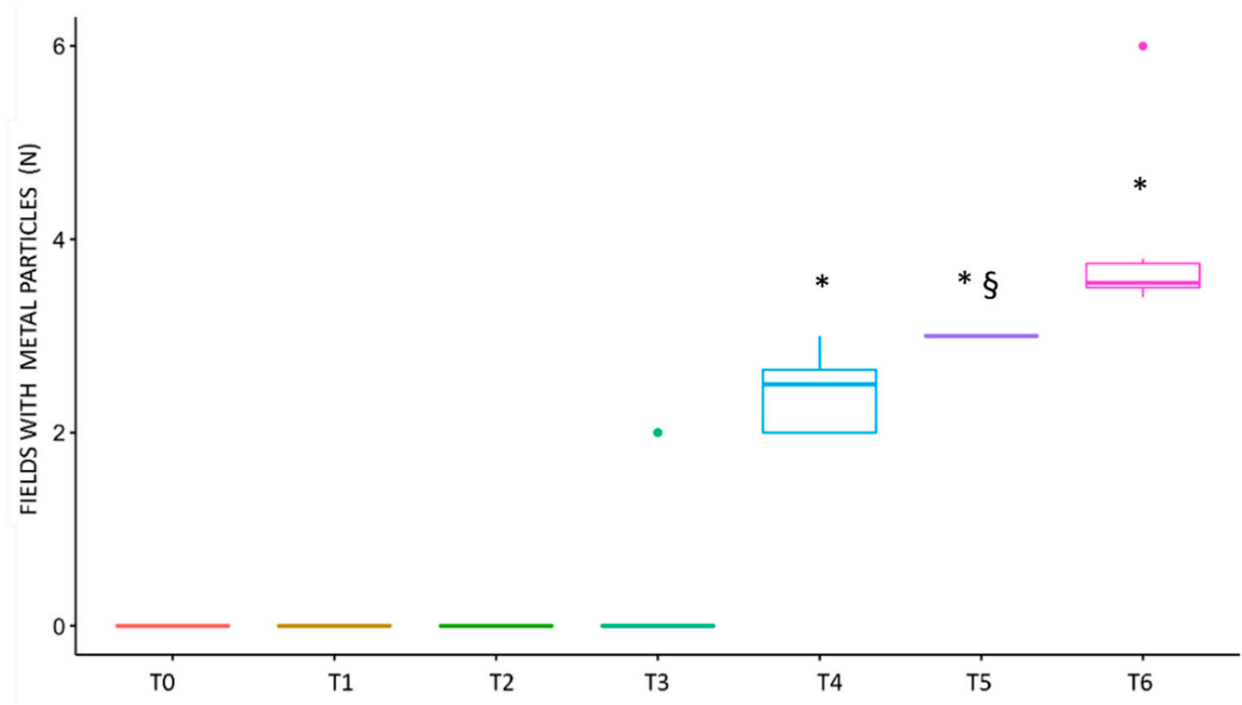

Figure 10. Graphical representation of the spotted fields with metal particles. The difference in the number of fields with metal debris was significant between $\mathrm{T} 5$ and $\mathrm{T} 0$, as revealed by the Wilcoxon test, indicated on the graph with §. The Bonferroni post-hoc analysis revealed a statistically significant difference in samples T4, T5, and T6 ( $p$ value $<0.05)$, indicated on the graph with *.

\section{Discussion}

The present study aimed to assess by means of SEM-EDX methods, the presence of metal debris in implant sites prepared in animal bone tissue using guided surgical templates, simulating, as much as possible, the operative condition. A critical factor that appeared to influence the release of metal particles is the cycles of usages of the kit and the consequent wear of the surgical burs. In the examined samples, the metal particles deposition is almost absent up to 10 preparations, despite the lack of irrigation and aspiration; instead of at 30 preparations, few particles were observable at the SEM-EDX.

The quality of found elements $(\mathrm{Cr}, \mathrm{Si}, \mathrm{Fe}, \mathrm{Al}, \mathrm{Ti})$ indicates the metal debris was both from the drill bits and likely from the sleeve portion of surgical guide.

The SEM-EDX methodology indeed provides a representation of the sample surface and the composition of the chosen areas, and eventual presence of metals with a sensitivity to $0.1 \mathrm{wt} \%$ [30]. The main limit of the study is represented by the use of one analytical method, and the absence of adjunctive methods such as Fourier transform infrared spectroscopy (FTIR). Indeed, the FTIR can provide information of additional chemical and organic contaminants and can be considered in future in vivo studies.

Indeed Liu et al., used the FTIR-imaging to not only assess the presence of metal in replaced hip joints, but by means of this tool, it was possible to appreciate areas with different types of cells, organic debrides, and metal oxides [31].

The presence of debris, which might derive from the prosthesis and/or from the surgical instruments, might contribute to the onset of inflammatory disease and to the observed sterile osteolysis [10].

The dental implant survival rate over a long-term period $\geq 20$ years has been $97 \%$ in cases of a single implant, $90 \%$ in cases of small edentulism, and $80 \%$ to $95.5 \%$ in cases of edentulous jaws [32]. The etiopathogenesis and the treatment strategies of the periimplantitis are a continuous object of research. So far, a correct prosthetic project, professional hygiene sessions, mechanical and chemical biofilm removal, photodynamic therapies, and antibiotic administrations have been considered as proper preventive and treatment procedures to maintain the health of implants and in general of the patient, to assure an appropriate quality of life $[4,5,32]$. The titanium alloys surfaces of the implants, both dental and orthopedic, maintain an excellent metal-bone interface. Metal particles' diffusion in hard and soft tissues around the prostheses has been observed, mainly in orthopedic studies, due to the corrosion of the prosthetic surfaces [33]. The diffusion can occur both 
in the operative and post-operative phases, with the consequent triggering of those immunological processes just mentioned [16]. If the source of the post-operative diffusion can be seen in the implants, the source of the operative diffusion can be represented by the rotary surgical instruments [10]. Thus, metal debris plays a dual role in stimulating inflammation by directly activating macrophages and acting as haptens, promoting type IV immune responses (delayed hypersensitivity) [12,34-36]. Recently, Ozan et al. reported how the metal debris could derive both from the drills and the sleeves present in the guide templates, in the absence of irrigation, simulating the conditions of the surgical protocol of guided implantology [26]. This protocol envisages the use of somewhat invasive surgical guides, which, precisely because of their size, do not allow abundant irrigation of the implant preparation site during processing. Similar to our study, the data reported by Ozan et al. confirm how the increase in the number of times the drill is used determines the mass loss of the drill wear and the guide sleeve [26]. Irrigation of the implant site with a cooled physiological solution is strongly recommended to control the working temperature to avoid damage to the bone tissue and because overheating worsens the performance of the implant preparation drills. This results in more significant wear loss and reduced cutting efficiency [37]. In addition to these fundamental functions, we can assume that continuous irrigation on the site under preparation carries out a constant washing that removes any metal residues, resulting from the wear of the drills, from the area affected by the intervention. Therefore, the lack of adequate irrigation in guided surgery might be possible due to the presence of the surgical guide, and the number of uses of the drills determines the deposit of metal residues in the implant site with the risk of starting aseptic osteolysis.

An appropriate quality control of the wear of surgical instruments, as well as an appropriate irrigation and aspiration of the implant site would limit the presence of metal debris in the implant site.

\section{Conclusions}

According to the study results, the presence of metal residues in the implant site, due to the wear of the drills used for the surgical operation, has been demonstrated increasingly according to the cycles of use of the drills. We have observed that in the first three groups, there is no presence of metals. This is evident in groups T3 and T4. Finally, the presence of metal residues becomes significant in the study's last two groups of samples.

Author Contributions: Conceptualization, G.F. (Giovanni Falisi) and G.B.; methodology, S.B. (Sara Bernardi); formal analysis, D.P. and M.S.; investigation, S.R. and S.B. (Sara Bernardi); resources, R.G. and G.F. (Giovanni Falisi); writing-original draft preparation, G.F. (Giordano Foffo), S.B. (Sara Bernardi) and S.B. (Serena Bianchi); writing-review and editing, C.D.P., G.F. (Giovanni Falisi) and R.G. All authors have read and agreed to the published version of the manuscript.

Funding: AB DENTAL DEVICES LTD ASHDOD-Israel.

Institutional Review Board Statement: The study was conducted according to the guidelines of the Declaration of Helsinki. Institutional Review Board was not required given the nature of the animal samples.

Informed Consent Statement: Not applicable.

Data Availability Statement: Data will be available upon reasonable request to the corresponding authors.

Conflicts of Interest: The authors declare no conflict of interest.

\section{References}

1. Misch, C.E.; Perel, M.L.; Wang, H.L.; Sammartino, G.; Galindo-Moreno, P.; Trisi, P.; Steigmann, M.; Rebaudi, A.; Palti, A.; Pikos, M.A.; et al. Implant success, survival, and failure: The International Congress of Oral Implantologists (ICOI) Pisa Consensus Conference. Implant. Dent. 2008, 17, 5-15. [CrossRef]

2. Özcan, M.; Hämmerle, C. Titanium as a reconstruction and implant material in dentistry: Advantages and pitfalls. Materials 2012, 5, 1528-1545. [CrossRef] 
3. Bernardi, S.; Bianchi, S.; Botticelli, G.; Rastelli, E.; Tomei, A.R.; Palmerini, M.G.; Continenza, M.A.; Macchiarelli, G. Scanning electron microscopy and microbiological approaches for the evaluation of salivary microorganisms behaviour on anatase titanium surfaces: In vitro study. Morphologie 2018, 102,1-6. [CrossRef]

4. Bianchi, S.; Fantozzi, G.; Bernardi, S.; Antonouli, S.; Continenza, M.A.; Macchiarelli, G. Commercial oral hygiene products and implant collar surfaces: Scanning electron microscopy observations. Can. J. Dent. Hyg. 2020, 54, 26-31. [PubMed]

5. Bernardi, S.; Bianchi, S.; Tomei, A.R.; Continenza, M.A.; Macchiarelli, G. Microbiological and SEM-EDS evaluation of titanium surfaces exposed to periodontal gel: In vitro study. Materials 2019, 12, 1448. [CrossRef] [PubMed]

6. Ercoli, C.; Funkenbusch, P.D.; Lee, H.J.; Moss, M.E.; Graser, G.N. The influence of drill wear on cutting efficiency and heat production during osteotomy preparation for dental implants: A study of drill durability. Int J. Oral Maxillofac. Implant. 2004, 19, 335-349.

7. Tretto, P.H.W.; Fabris, V.; Cericato, G.O.; Sarkis-Onofre, R.; Bacchi, A. Does the instrument used for the implant site preparation influence the bone-implant interface? A systematic review of clinical and animal studies. Int. J. Oral Maxillofac. Surg. 2019, 48, 97-107. [CrossRef] [PubMed]

8. Scarano, A.; Carinci, F.; Quaranta, A.; Di Iorio, D.; Assenza, B.; Piattelli, A. Effects of bur wear during implant site preparation: An in vitro study. Int. J. Immunopathol. Pharm. 2007, 20, 23-26. [CrossRef]

9. Pedowitz, R.A.; Billi, F.; Kavanaugh, A.; Colbert, A.; Liu, S.; Savoie, F.H.; You, Z. Arthroscopic surgical tools: A source of metal particles and possible joint damage. Arthrosc. J. Arthrosc. Relat. Surg. 2013, 29, 1559-1565. [CrossRef] [PubMed]

10. Berryman, Z.; Bridger, L.; Hussaini, H.M.; Rich, A.M.; Atieh, M.; Tawse-Smith, A. Titanium particles: An emerging risk factor for peri-implant bone loss. Saudi Dent. J. 2020, 32, 283-292. [CrossRef]

11. Messous, R.; Henriques, B.; Bousbaa, H.; Silva, F.S.; Teughels, W.; Souza, J.C.M. Cytotoxic effects of submicron- and nano-scale titanium debris released from dental implants: An integrative review. Clin. Oral Investig. 2021, 25, 1627-1640. [CrossRef] [PubMed]

12. Lugowski, S.J.; Smith, D.C.; McHugh, A.D.; Van Loon, J.C. Release of metal ions from dental implant materials in vivo: Determination of Al, Co, Cr, Mo, Ni, V, and Ti in organ tissue. J. Biomed. Mater. Res. 1991, 25, 1443-1458. [CrossRef] [PubMed]

13. Coen, N.; Kadhim, M.A.; Wright, E.G.; Case, C.P.; Mothersill, C.E. Particulate debris from a titanium metal prosthesis induces genomic instability in primary human fibroblast cells. Br. J. Cancer 2003, 88, 548-552. [CrossRef] [PubMed]

14. Goodman, S.B. Wear particles, periprosthetic osteolysis and the immune system. Biomaterials 2007, 28, 5044-5048. [CrossRef]

15. Schoon, J.; Hesse, B.; Rakow, A.; Ort, M.J.; Lagrange, A.; Jacobi, D.; Winter, A.; Huesker, K.; Reinke, S.; Cotte, M.; et al. Metal-specific biomaterial accumulation in human peri-implant bone and bone marrow. Adv. Sci. 2020, 7, 2000412. [CrossRef]

16. Senna, P.; Antoninha Del Bel Cury, A.; Kates, S.; Meirelles, L. Surface damage on dental implants with release of loose particles after insertion into bone. Clin. Implant. Dent. Relat. Res. 2015, 17, 681-692. [CrossRef]

17. Sridhar, S.; Abidi, Z.; Wilson, T.G.J.; Valderrama, P.; Wadhwani, C.; Palmer, K.; Rodrigues, D.C. In vitro evaluation of the effects of multiple oral factors on dental implants surfaces. J. Oral Implant. 2016, 42, 248-257. [CrossRef]

18. Caton, J.G.; Armitage, G.; Berglundh, T.; Chapple, I.; Jepsen, S.; Kornman, K.S.; Mealey, B.L.; Papapanou, P.N.; Sanz, M.; Tonetti, M.S. A new classification scheme for periodontal and peri-implant diseases and conditions-Introduction and key changes from the 1999 classification. J. Clin. Periodontol. 2018, 45, S1-S8. [CrossRef]

19. Lafaurie, G.I.; Sabogal, M.A.; Castillo, D.M.; Rincón, M.V.; Gómez, L.A.; Lesmes, Y.A.; Chambrone, L. Microbiome and microbial biofilm profiles of peri-implantitis: A systematic review. J. Periodontol. 2017, 88, 1066-1089. [CrossRef]

20. Fragkioudakis, I.; Tseleki, G.; Doufexi, A.E.; Sakellari, D. Current concepts on the pathogenesis of peri-implantitis: A narrative review. Eur. J. Dent. 2021, 15, 379-387. [CrossRef]

21. Di Murro, B.; Moretti, M.; De Smaele, E.; Letizia, C.; Lubrano, C.; Passarelli, P.C.; D’Addona, A.; Pompa, G.; Papi, P. Microbiological profiles of dental implants in metabolic syndrome patients: A case-control study. Antibiotics 2021, 10, 452. [CrossRef] [PubMed]

22. Harris, W.H. Conquest of a worldwide human disease: Particle-induced periprosthetic osteolysis. Orthop. Relat. Res. 2004, 429, 439-442. [CrossRef] [PubMed]

23. Lybrand, K.E.; Althausen, P.L. The role of value-based implants in orthopedic trauma. Orthop. Clin. Am. 2018, 49, 437-443. [CrossRef]

24. Bitar, D.; Parvizi, J. Biological response to prosthetic debris. World Orthop. 2015, 6, 172-189. [CrossRef]

25. Fretwurst, T.; Nelson, K.; Tarnow, D.P.; Wang, H.L.; Giannobile, W.V. Is metal particle release associated with peri-implant bone destruction? An emerging concept. Dent. Res. 2018, 97, 259-265. [CrossRef] [PubMed]

26. Ozan, O.; Şeker, E.; Çakmak, G.; Guo, X.; Yilmaz, B. Effect of guide sleeve material, region, diameter, and number of times drills were used on the material loss from sleeves and drills used for surgical guides: An in vitro study. Prosthet. Dent. 2021, 1-8. [CrossRef]

27. Pearce, A.I.; Richards, R.G.; Milz, S.; Schneider, E.; Pearce, S.G. Animal models for implant biomaterial research in bone: A review. Eur. Cell Mater. 2007, 13, 1-10. [CrossRef]

28. Misch, C.E. Bone character: Second vital implant criterion. Today 1988, 7, 39-40.

29. Vesley, D.; Langholz, A.C.; Rohlfing, S.R.; Foltz, W.E. Fluorimetric detection of a bacillus stearothermophilus spore-bound enzyme, alpha-d-glucosidase, for rapid indication of flash sterilization failure. Appl. Environ. Microbiol. 1992, 58, 717-719. [CrossRef]

30. Walzak, M.J.; Davidson, R.; Biesinger, M. The use of XPS, FTIR, SEM/EDX, contact angle, and AFM in the characterization of coatings. J. Mater. Eng. Perform. 1998, 7, 317-323. [CrossRef] 
31. Liu, S.; Hall, D.J.; McCarthy, S.M.; Jacobs, J.J.; Urban, R.M.; Pourzal, R. Fourier transform infrared spectroscopic imaging of wear and corrosion products within joint capsuletissue from total hip replacements patients. Biomed. Mater. Res. 2020, 108B, 513-526. [CrossRef]

32. Frisch, E.; Wild, V.; Ratka-krüger, P.; Kirstin, V.; Sennhenn-kirchner, S. Long-term results of implants and implant-supported prostheses under systematic supportive implant therapy: A retrospective 25-year study. Clin. Implant. Dent. Relat. 2020, 22, 689-696. [CrossRef]

33. Matusiewicz, H. Potential release of in vivo trace metals from metallic medical implants in the human body: From ions to nanoparticles-A systematic anal-tical review. Acta Biomater. 2014, 10, 2379-2403. [CrossRef]

34. Rauner, M.; Sipos, W.; Pietschmann, P. Osteoimmunology. Int. Arch. Allergy Immunol. 2007, 143, 31-48. [CrossRef] [PubMed]

35. Holt, G.; Murnaghan, C.; Reilly, J.; Meek, R.M.D. The biology of aseptic osteolysis. Clin. Orthop. Relat. Res. 2007, 460, 240-252. [CrossRef] [PubMed]

36. Cadosch, D.; Gautschi, O.P.; Chan, E.; Simmen, H.P.; Filgueira, L. Titanium induced production of chemokines CCL17/TARC and CCL22/MDC in human osteoclasts and osteoblasts. J. Biomed. Mater. Res. A 2010, 92, 475-483. [CrossRef]

37. Harris, B.H.; Kohles, S.S. Effects of mechanical and thermal fatigue on dental drill performance. Int. J. Oral Maxillofac. Implant. 2001, 16, 819-826. 